\title{
Predicting survival in anaplastic astrocytoma patients in a single-center cohort of 108 patients
}

Helena C. W. Wahner ${ }^{1}$, Malte Träger ${ }^{1}$, Katja Bender $^{1}$, Leonille Schweizer ${ }^{2,3}$, Julia Onken ${ }^{4}$, Carolin Senger ${ }^{1}$, Felix Ehret ${ }^{1}$, Volker Budach ${ }^{1}$ and David Kaul' ${ }^{1,3^{*}}$ (D)

\begin{abstract}
Background: Current guidelines for the treatment of anaplastic astrocytoma (AA) recommend maximal safe resection followed by radiotherapy and chemotherapy. Despite this multimodal treatment approach, patients have a limited life expectancy. In the present study, we identified variables associated with overall survival (OS) and constructed a model score to predict the OS of patients with AA at the time of their primary diagnosis.
\end{abstract}

Methods: We retrospectively evaluated 108 patients with newly diagnosed AA. The patient and tumor characteristics were analyzed for their impact on OS. Variables significantly associated with OS on multivariable analysis were included in our score. The final algorithm was based on the 36-month survival rates corresponding to each characteristic.

Results: On univariate analysis, age, Karnofsky performance status, isocitrate dehydrogenase status, and extent of resection were significantly associated with OS. On multivariable analysis all four variables remained significant and were consequently incorporated in the score. The total score ranges from 20 to 33 points. We designated three prognostic groups: A (20-25), B (26-29), and C (30-33 points) with 36-month OS rates of 23\%, 71\%, and 100\%, respectively. The OS rate at 5 years was $8 \%$ in group $A, 61 \%$ in group $B$ and $88 \%$ in group $C$.

Conclusions: Our model score predicts the OS of patients newly diagnosed with AA and distinguishes patients with a poor survival prognosis from those with a greater life expectancy. Independent and prospective validation is needed. The upcoming changes of the WHO classification of brain tumors as well as the practice changing results from the CATNON trial will most likely require adaption of the score.

Keywords: Score, Anaplastic astrocytoma, Overall survival, Glioma

\section{Background}

Anaplastic astrocytoma (AA) is a diffusely infiltrating, malignant primary brain tumor. An update of the World Health Organization (WHO) classification in 2016 established new diagnostic groups based on histological phenotypes and genotypes, which are linked to unique

*Correspondence: david.kaul@charite.de

${ }^{1}$ Department of Radiation Oncology, Charité University Hospital Berlin, Augustenburger Platz 1, 13353 Berlin, Germany

Full list of author information is available at the end of the article biological behaviors and treatment responses [1]. WHO grade III tumors are distinguished in case of oligodendroglioma and AA. They differ in their molecular profiles, and patients have a distinct median age at diagnosis and median survival. Oligodendrogliomas typically present with $1 \mathrm{p} / 19 \mathrm{q}$-codeletion combined with IDH-mutation and have the best outcome of all WHO grade III tumors. AA can be further differentiated into subgroups based on isocitrate dehydrogenase (IDH) type 1 and 2 mutation status. The prognosis of IDH-mutant AA is intermediate, original author(s) and the source, provide a link to the Creative Commons licence, and indicate if changes were made. The images or other third party material in this article are included in the article's Creative Commons licence, unless indicated otherwise in a credit line to the material. If material is not included in the article's Creative Commons licence and your intended use is not permitted by statutory regulation or exceeds the permitted use, you will need to obtain permission directly from the copyright holder. To view a copy of this licence, visit http://creativecommons.org/licenses/by/4.0/. The Creative Commons Public Domain Dedication waiver (http://creativeco mmons.org/publicdomain/zero/1.0/) applies to the data made available in this article, unless otherwise stated in a credit line to the data. 
whereas IDH-wildtype AA is linked to a poor prognosis, bearing many similarities to glioblastoma (GBM).

As our knowledge of molecular markers has rapidly evolved, studies performed before the 2016 WHO classification update did not distinguish between the separate entities, as we currently do. Key research in the past decade lacked a clear distinction between AA and oligodendroglioma. In the NOA-04 study, molecular subgroup analysis of a mixed cohort of patients with WHO grade III tumors demonstrated associations of IDH mutations, $1 \mathrm{p} / 19 \mathrm{q}$-codeletion, and $\mathrm{O}^{6}$-methylguanine-DNA-methyltransferase (MGMT) promoter methylation with better progression-free survival (PFS) and overall survival (OS). Together with a young age, a high initial Karnofsky Performance Status (KPS) and the presence of oligodendroglial histological characteristics are generally the most important factors associated with better outcomes of WHO grade III gliomas [2].

Ideal treatments for the different subgroups as defined by the genotype remain uncertain. Radiotherapy (RT), chemotherapy (CTx), and a combination of both have all proven to be effective measures in primary and secondary treatment for different subgroups of diffuse glioma [2-4]. Current treatment for AA consists of maximal safe resection followed by a combination of temozolomide (TMZ)-based chemotherapy and RT [5]. Studies specifically designed to investigate AA treatments are rare. The current recommendations are partly based on preliminary results of the CATNON trial, which compared the effects of RT alone, RT combined with either concomitant or adjuvant TMZ, or RT with both concomitant and adjuvant TMZ on PFS and OS. The first interim results published in 2017 demonstrated a benefit for the two study groups receiving adjuvant CTx [6]. This finding was rapidly adapted for routine clinical use, as data for evidence-based treatment of this specific diagnosis are sparse. The second interim results from 2019 included the first molecular analysis, which limited the benefit of adjuvant TMZ to IDH-mutant AA. The results also demonstrated that concomitant TMZ did not increase OS in the entire study cohort, though a trend towards benefit was present in IDH-mutant tumors [7].

Prognostic scores for the heterogeneous entity "glioma" are well established, especially for recurrent disease. One of the earliest prognostic scores for re-irradiation of recurring glioma was published by Combs and colleagues in 2013 [8]. It was subsequently improved by Kessel et al., adding further predictive variables to the scoring system $[9,10]$. In 2018, Niyazi et al. presented a re-irradiation score to predict post-recurrence survival in patients with glioma [11]. Recently, Straube et al. published a score specifically designed to predict survival in elderly patients with newly diagnosed GBM [12]. These scores all have in common that they are based on cohorts that either consist only (Straube et al.) or mostly (Kessel et al., Niyazi et al.) of patients with GBM or low-grade glioma and GBM (Combs et al.) [8, 9, 11, 12]. AA has been underrepresented in this research, and there is a need for more specific scoring systems to predict survival outcomes. Developing a neurooncological treatment strategy for patients with AA presents clinicians with the challenge of balancing maximally effective treatment with quality of life. A diagnosis-specific score applicable at the time of initial diagnosis can help objectify a patient's prognosis. In the present study, we aimed to identify variables associated with OS in patients with AA. Our goal was to construct a simple score specifically for this diagnostic subgroup that factored in the information available at the point of primary treatment assessment. To our knowledge, no scores based on a homogeneous cohort of patients with AA have been developed and published to date.

\section{Methods}

This was a single-center, retrospective, observational study. Ethical approval was obtained from the Charité Review Board (EA2/150/20). The patient database of Charité Universitätsmedizin Berlin was searched for patients with AA who had received treatment between January 2010 and January 2020. We researched each patient's medical record to assess the following eligibility criteria: age $\geq 18$ years, primary histopathological diagnosis of a WHO grade III tumor, absence of $1 \mathrm{p} / 19 \mathrm{q}$ codeletion, and primary treatment received at Charité Universitätsmedizin Berlin. Treatment decisions at our center are made by a multidisciplinary tumor board and reflect the individual patient's wishes. As part of a narrow follow-up schedule, all patients receive consultations and contrast-enhanced magnetic resonance imaging (MRI) controls every 3 months. Overall, 108 eligible cases were included. We then reviewed the respective medical records to retrieve information including basic patient characteristics (sex, age, KPS), histopathology of primary diagnosis (IDH status, MGMT promoter methylation status), primary therapy (extent of resection; RT including dosage, fractionation, and planning target volume; CTx including substance, concomitant, or adjuvant administration), disease progression, secondary therapy, last contact, and death.

Six characteristics were analyzed for their potential association with OS: sex (female vs. male), age at the time of surgery (divided by the median age, $<41$ vs. $\geq 41$ years), KPS (less than vs. greater than or equal to the median of 90\%), IDH status (mutant vs. wildtype), MGMT promoter methylation status (methylated vs. non-methylated), and 
resection status after primary surgery (biopsy vs. subtotal resection vs. gross total resection). The KPS was determined postoperatively. IDH mutation was determined by immunostaining. If IDH R132H was negative, additional pyrosequencing for IDH1/2 was performed. The extent of resection was defined based on postoperative contrastenhanced MRI.

Statistical analysis was performed using IBM SPSS Statistics for Mac OS, version 26.0 (IBM Corp., Armonk, NY, USA). A $p$ value $<0.05$ was considered significant. Univariate analysis (UVA) was performed using the logrank test. Variables that proved to be significant in UVA were included in a multivariable Cox regression analysis (MVA). We included characteristics that were independent predictors of OS in MVA in our scoring system. To generate a subscore for each variable, the 36-month survival rate for each characteristic was divided by 10 . The subscores of all significant parameters were totaled to result in the score for each patient. This methodological approach has been demonstrated in other studies [12, 13].

\section{Results}

An overview of the patient and tumor characteristics most relevant for the construction of a prognostic score is presented in Table 1. Primary treatment modalities varied in the investigated cohort. The majority of patients had undergone either CTx alone or RT with concomitant and adjuvant CTx. Almost all patients who underwent RT received total doses of $\geq 59.2$ Gy. Normofractionated (1.8-2.0 Gy single dose per day) and accelerated hyperfractionated (1.6 Gy twice daily) RT were the most common fractionation schemes. One patient was treated in line with the Nordic glioma regimen and received hypofractionated treatment with 34 Gy in 10 fractions of 3.4 Gy [14]. If concomitant or adjuvant CTx was administered in the primary setting, the applied drug was almost exclusively TMZ. The standard concomitant dose was $75 \mathrm{mg} / \mathrm{m}^{2}$ daily. Standard adjuvant chemotherapy with TMZ included 150 or $200 \mathrm{mg} / \mathrm{m}^{2} / \mathrm{d}$ TMZ administered on 5 consecutive days as part of a 28-day cycle. Most patients received 12 cycles. If interruption or termination occurred at any point of treatment, we attempted to document the duration and reason. When comparing the different treatment arms of our cohort, patients receiving CTx only $(44.4 \%, \mathrm{n}=49)$ showed significantly better survival ( $p$ 0.001) than those who received any kind of combined radiochemotherapy ( $\mathrm{RCTx}, 31.5 \%, \mathrm{n}=34$ ). This can be explained by substantial differences in the frequency of IDH-wildtype tumors: Of those 34 patients receiving RCTx, 7 (20.6\%) had IDH-wildtype tumors. In contrast, there were only $2(4.2 \%)$ IDH-wildtype tumors in the 49 patients strong CTx only group. This
Table 1 Patient and tumor characteristics

\begin{tabular}{|c|c|c|}
\hline & $\mathrm{n}$, median (min-max) & $\%$ \\
\hline \multicolumn{3}{|l|}{ Sex } \\
\hline Male & 64 & 59.3 \\
\hline Female & 44 & 40.7 \\
\hline Age (years) & $41(22-87)$ & \\
\hline$<41$ & 53 & 49.1 \\
\hline$\geq 41$ & 55 & 50.9 \\
\hline KPS (\%) & $90(60-100)$ & \\
\hline$<90$ & 25 & 23.1 \\
\hline$\geq 90$ & 69 & 63.9 \\
\hline Unknown & 14 & 13.0 \\
\hline \multicolumn{3}{|l|}{ IDH } \\
\hline Mutant & 84 & 77.8 \\
\hline Wildtype & 9 & 8.3 \\
\hline Unknown & 15 & 13.9 \\
\hline \multicolumn{3}{|l|}{ MGMT } \\
\hline Methylated & 86 & 79.6 \\
\hline Non-methylated & 19 & 17.6 \\
\hline Unknown & 3 & 2.8 \\
\hline \multicolumn{3}{|l|}{ 1p/19q-Codeletion } \\
\hline Non-codeleted & 108 & 100.0 \\
\hline Codeleted & 0 & 0.0 \\
\hline Unknown & 0 & 0.0 \\
\hline \multicolumn{3}{|l|}{ Resection } \\
\hline Biopsy & 13 & 12.0 \\
\hline Subtotal resection & 25 & 23.1 \\
\hline Gross total resection & 65 & 60.2 \\
\hline Unknown & 5 & 4.6 \\
\hline \multicolumn{3}{|l|}{ Treatment after surgery } \\
\hline CTx mono & 48 & 44.4 \\
\hline RT mono & 8 & 7.4 \\
\hline $\mathrm{RT}+\operatorname{concCTx}$ & 5 & 4.6 \\
\hline$R T+\operatorname{adj} C T x$ & 5 & 4.6 \\
\hline $\mathrm{RT}+\operatorname{conc} C \mathrm{~T} x+\operatorname{adj} C T x$ & 20 & 18.5 \\
\hline RT, CTx unknown & 6 & 5.6 \\
\hline No RT, CTx unknown & 3 & 2.8 \\
\hline Unknown & 13 & 12.0 \\
\hline
\end{tabular}

KPS Karnofsky performance status, IDH isocitrate dehydrogenase type 1 and 2, MGMT O6-methylguanine-DNA-methyltransferase, CTx chemotherapy, $R T$ radiotherapy, concCTx concomitant chemotherapy, adjCTx adjuvant chemotherapy

distribution is in line with the general recommendation for IDH-wildtype tumors to receive combination therapy.

Median follow-up to last contact or death was 29.5 months. Forty patients underwent salvage therapy for recurrent disease. Salvage treatment regimens were quite heterogeneous. Nine patients received trimodal therapy with re-resection followed by RCTx. Eight patients had re-resection followed by either radiotherapy 
or systemic therapy. Six patients underwent re-resection without adjuvant treatment. Seven patients received RCTx without re-resection. Five patients received systemic monotherapy and another five patients received only radiotherapy without re-resection.

Age $(p<0.001)$, KPS $(p<0.001)$, IDH status $(p 0.006)$, and extent of resection $(p<0.001)$ were significantly associated with OS. Sex and MGMT promoter status failed to show significance (Table 2). On MVA, age $(p 0.011)$, KPS ( $p 0.033)$, IDH status $(p 0.042)$, and extent of resection $(p<0.001)$ all remained significant (Table 3). Kaplan-Meier curves are provided for these four characteristics that had a significant impact on OS in UVA and MVA (Fig. 1). The scoring system was based on the 36-month OS rates divided by 10 . Table 4 provides an overview of the corresponding scores attributed to each characteristic. After adding the scores of the four characteristics for each patient, we obtained total scores ranging from 20 to 33 points (Fig. 2). Next, we determined three prognostic groups based on the 36-month survival rates of the patient scores: A (20-25 points), B (26-29 points), and C (3033 points). The survival rates for the three groups were $75 \%, 93 \%$, and $100 \%$ at 12 months; $23 \%, 71 \%$, and $100 \%$
Table 3 MVA for parameters significant in UVA

\begin{tabular}{llcr}
\hline & HR & $\mathbf{9 5 \% ~ C l}$ & $p$ value \\
\hline $\begin{array}{l}\text { Age (years) } \\
<41 \text { versus } \geq 41\end{array}$ & 5.123 & $1.46-17.97$ & $\mathbf{0 . 0 1 1}$ \\
$\begin{array}{l}\text { KPS (\%) } \\
<90 \text { versus } \geq 90\end{array}$ & 0.406 & $0.12-0.93$ & $\mathbf{0 . 0 3 3}$ \\
IDH & & & \\
Mutant versus Wildtype & 2.777 & $1.04-7.43$ & $\mathbf{0 . 0 4 2}$ \\
$\begin{array}{l}\text { Resection } \\
\text { Biopsy }\end{array}$ & Reference & & \\
$\begin{array}{l}\text { Subtotal } \\
\text { Gross total }\end{array}$ & 0.157 & $0.05-0.52$ & $\mathbf{0 . 0 0 1}$ \\
\hline
\end{tabular}

Bold values indicate statistically significant $p$ values

HR hazard ratio, $\mathrm{Cl}$ confidence interval, KPS Karnofsky performance status, IDH isocitrate dehydrogenase type 1 and 2

at 36 months; and $8 \%, 61 \%$, and $88 \%$ at 60 months, respectively (Fig. 3). Median overall survival was only reached for group A at 16 months. When additionally tested for the two different primary treatment groups individually, our model score showed prognostic significance for both, the CTx only group $(p=0.021)$ and the RCTx group $(p<0.001)$.

Table 2 Univariate analyses

\begin{tabular}{|c|c|c|c|c|c|c|}
\hline & \multicolumn{6}{|c|}{ OS rate (\%) } \\
\hline & $12 \mathrm{~m}$ & $24 \mathrm{~m}$ & $36 \mathrm{~m}$ & $48 m$ & $p$ value & $n$ \\
\hline Sex & & & & & 0.524 & \\
\hline Male & 97 & 83 & 68 & 57 & & 64 \\
\hline Female & 92 & 70 & 70 & 70 & & 44 \\
\hline Age (years) & & & & & $<0.001$ & \\
\hline$<41$ & 100 & 91 & 91 & 85 & & 53 \\
\hline$\geq 41$ & 86 & 58 & 52 & 43 & & 55 \\
\hline KPS (\%) & & & & & $<0.001$ & \\
\hline$<90$ & 86 & 50 & 45 & 39 & & 25 \\
\hline$\geq 90$ & 95 & 86 & 80 & 77 & & 69 \\
\hline IDH & & & & & 0.006 & \\
\hline Mutant & 93 & 81 & 76 & 69 & & 84 \\
\hline Wildtype & 89 & 44 & 33 & 33 & & 9 \\
\hline MGMT & & & & & 0.428 & \\
\hline Methylated & 93 & 75 & 70 & 66 & & 86 \\
\hline Non-methylated & 88 & 66 & 57 & 47 & & 19 \\
\hline Resection & & & & & $<0.001$ & \\
\hline Biopsy & 74 & 37 & 19 & 19 & & 13 \\
\hline Subtotal & 91 & 75 & 69 & 60 & & 25 \\
\hline Gross total & 97 & 81 & 80 & 76 & & 65 \\
\hline
\end{tabular}

Bold values indicate statistically significant $p$ values

OS overall survival, KPS Karnofsky performance status, IDH isocitrate dehydrogenase type 1 and 2, MGMT O6-methylguanine-DNA-methyltransferase 

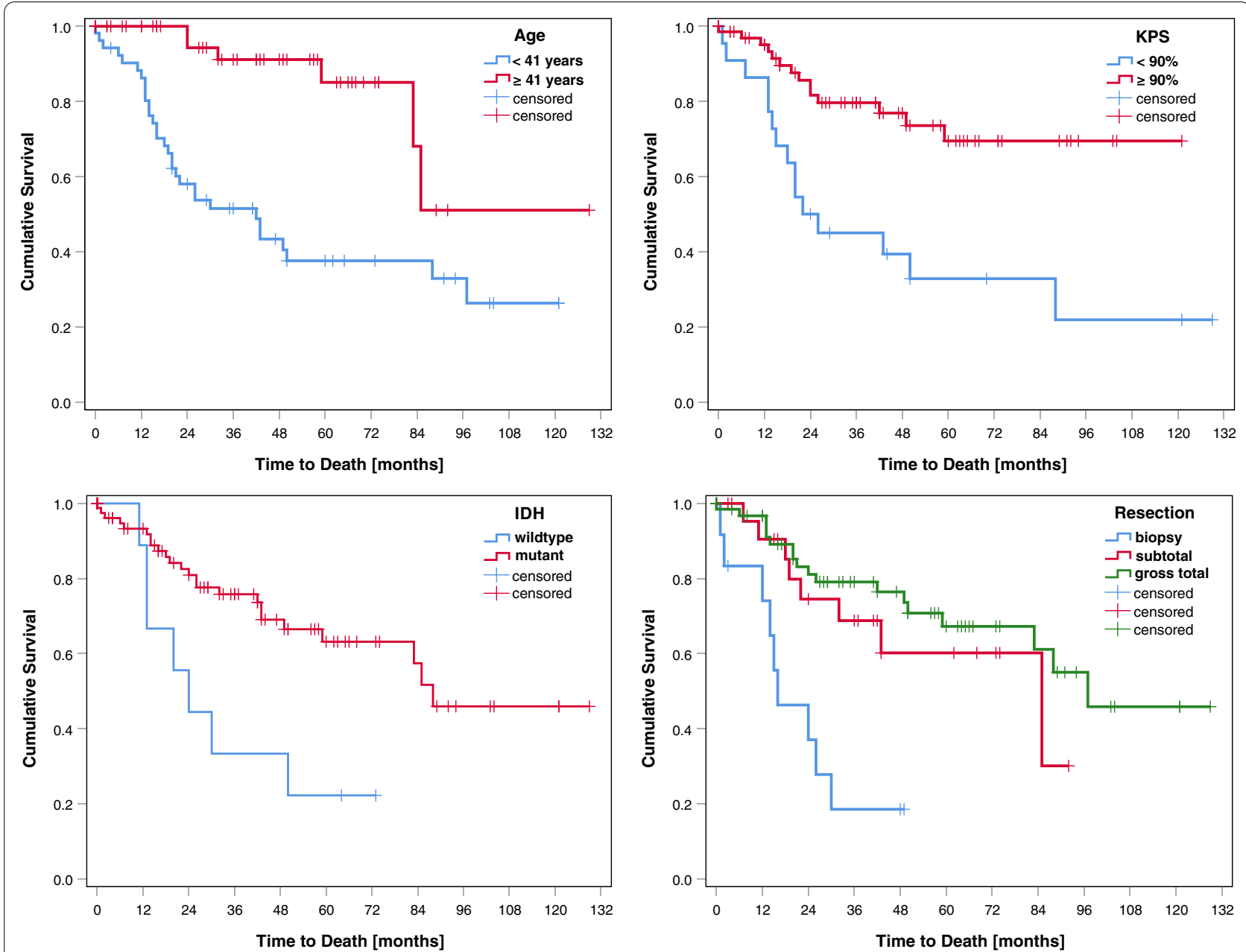

Fig. 1 Kaplan-Meier curves for parameters qualifying for inclusion in the score

Table 4 Scoring points

\begin{tabular}{lll}
\hline & 36 month OS rate (\%) & $\begin{array}{l}\text { Scoring } \\
\text { points }\end{array}$ \\
\hline $\begin{array}{ll}\text { Age (years) } \\
<41\end{array}$ & 91 & 9 \\
$\geq 41$ & 52 & 5 \\
KPS (\%) & & \\
$<90$ & 45 & 5 \\
$\geq 90$ & 80 & 8 \\
IDH & & \\
Mutant & 76 & 8 \\
Wildtype & 33 & 3 \\
Resection & & \\
Biopsy & 19 & 2 \\
Subtotal & 69 & 7 \\
Gross total & 80 & 8 \\
\hline OSoverlsurvit KPSKamosky & & \\
\hline
\end{tabular}

OS overall survival, KPS Karnofsky performance status, IDH isocitrate dehydrogenase type 1 and 2

\section{Discussion}

We present a prognostic score designed for the primary diagnosis of AA as defined by the updated WHO classification from 2016 [1]. As no curative treatment is available, balancing a therapy with quality of life is critical in the treatment planning for patients. A survival-predicting score that is applicable at the time of primary diagnosis is a helpful tool both in expert discussions and when consulting with patients and their families. We developed a score that enables the quick discrimination of prognostic groups with significant differences in life expectancy in our cohort. A tool like this might be useful in patient consultation and when discussing aggressive versus supportive treatment approaches. The assessment of our score requires four simple variables (age, KPS, IDH status and resection status) generally available at the time of histopathological confirmation of diagnosis. No additional diagnostics are required. 


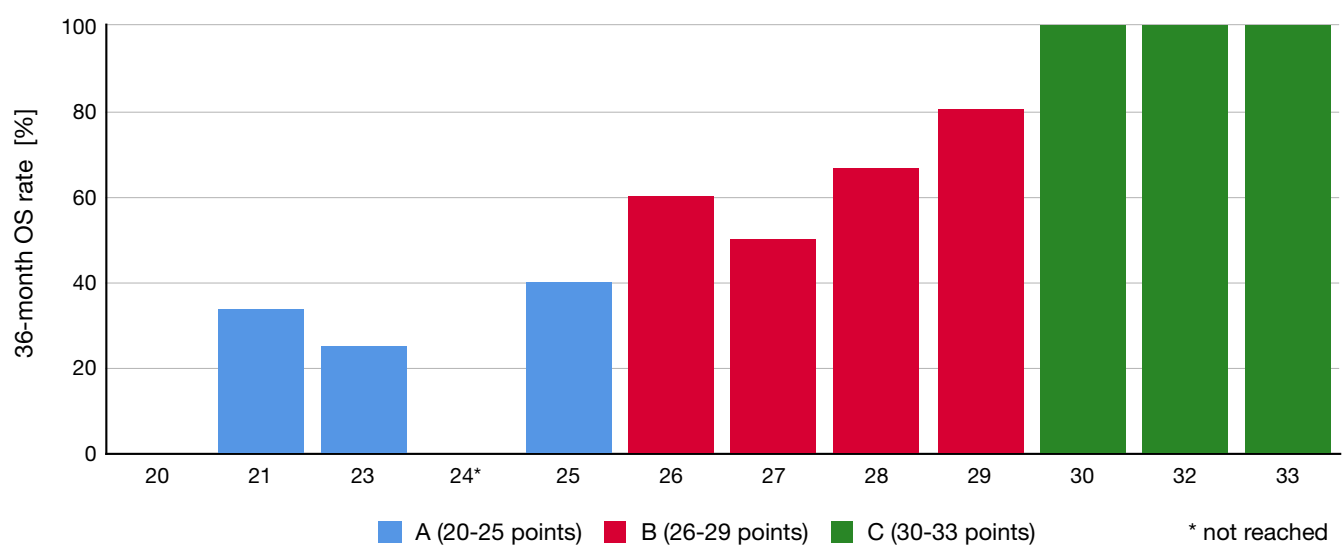

Fig. 2 Total score for individual patients and respective 36-month OS rate divided in three prognostic groups. * not reached

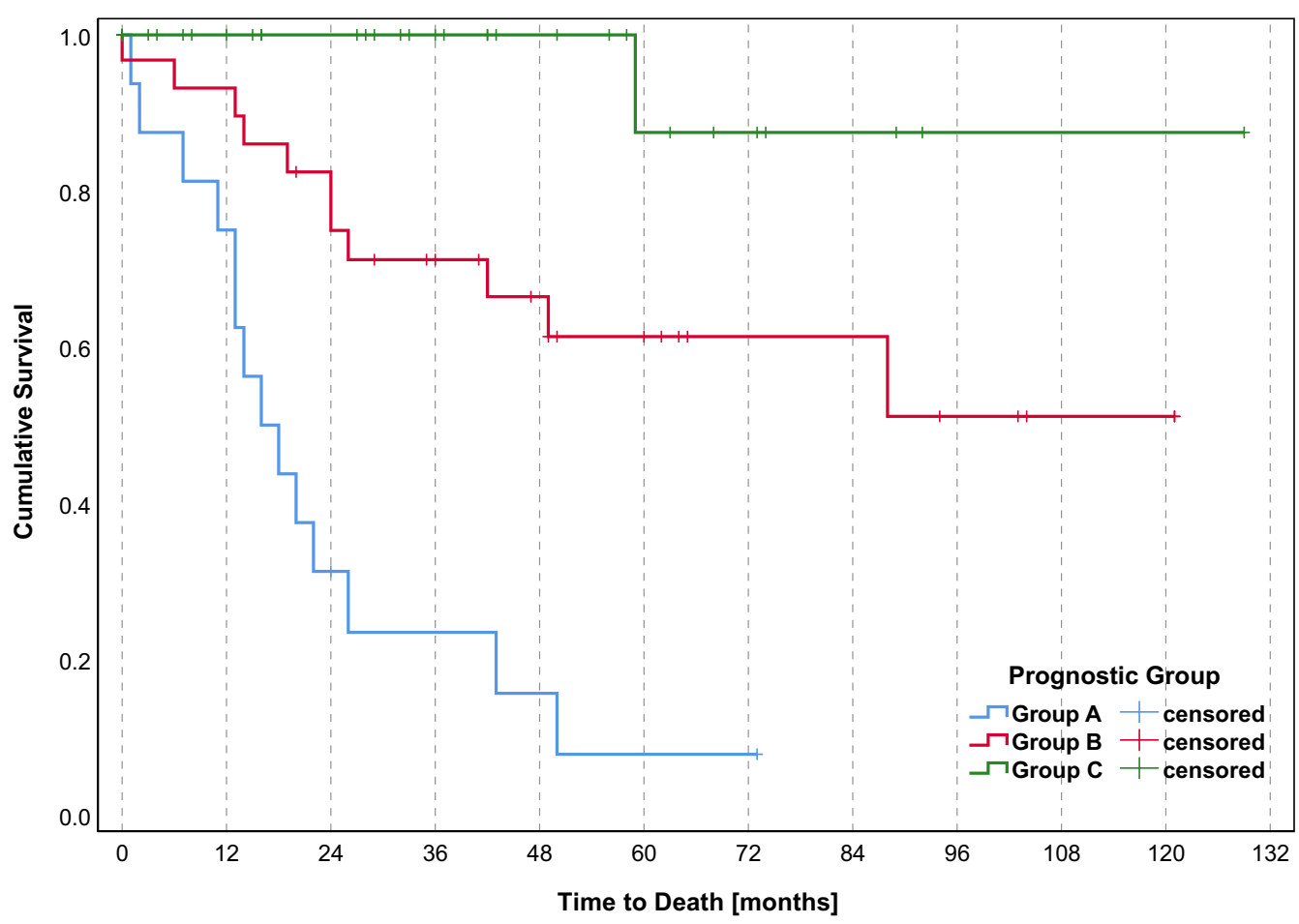

Fig. 3 Kaplan-Meier curve for the three prognostic groups $(p<0.001)$

The 2013 Combs score, one of the earliest prognostic scores for glioma, considers age, histology, and the time between initial RT and re-irradiation to predict survival after re-irradiation of recurrence [8]. It has repeatedly been reviewed in independent cohorts, and validation has not always been successful [15-17]. Failure to reproduce the findings established with the Combs score might partly be attributed to differences in cohort composition. For example, in 2014, Niyazi et al. attempted to reproduce the results in a patient cohort mainly treated with additional bevacizumab [18]. The 2018 re-irradiation risk score by Niyazi et al. factored in age, initial histology, and clinical performance status to predict post-recurrence survival. Their study also included an independent validation group [11]. Straube et al. recently presented a score to predict survival in elderly patients with newly diagnosed GBM, considering age, KPS, and MGMT promoter methylation [12]. As this is a GBMspecific score, it was based on a homogenous cohort of patients with GBM. All the scoring systems mentioned 
above were developed based on heterogeneous cohorts of patients with glioma. The proportion of patients with AA varied and was sometimes not specified. The Combs score is based on a mixed cohort of approximately $40 \%$ of patients with WHO grade II, $22 \%$ with WHO grade III, and approximately $38 \%$ with WHO grade IV tumors [8]. In the cohort investigated by Kessel et al., $64 \%$ of patients had GBM and 10\% had AA (16\% of WHO grade III tumors overall) [9]. In Niyazi et al's development cohort, $78 \%$ of patients had GBM and approximately $16 \%$ had WHO grade III tumors [11]. All authors, except for Combs et al., examined molecular parameters as potential factors in their scoring systems [8]. Kessel et al., Niyazi et al. and Straube and colleagues all considered MGMT promoter methylation status. Ultimately, it was only incorporated into the final score presented by Straube et al. Unlike our prognostic score, none of these scores include IDH status [10-12].

The importance of age at both the time of primary diagnosis and recurrence of glioma is underlined by its representation in all the mentioned prognostic scores $[8,10-12]$. The role of the KPS, however, is not as unambiguous as the role of age. Although KPS was not predictive of survival after re-irradiation in the original Combs score, this finding could not be replicated by Kessel et al., who then added KPS to the prognostic score $[9,10]$. When discussing the impact of resection status, careful differentiation between primary disease and recurrence is indicated. The modified Combs score incorporates whether re-resection has been performed and has shown borderline significance on MVA [10]. Niyazi et al. did not consider re-resection as a factor for score development [11]. Straube et al. considered the extent of the initial resection in UVA, but it failed to show a significant impact on MVA [12]. In our analysis, the results of UVAs and MVAs emphasize the importance of maximal safe resection as the only treatment-related prognosis-defining factor in our cohort.

In summary, the identified prognostic factors presented in our score are in line with earlier studies. A particular strength of our study is including only patients with AA, verified by tested absence of $1 \mathrm{p} / 19$-codeletion. Although we were able to define a score that shows significant prognostic strength, our study had several limitations.

The first limitation is the lack of molecular data. We were unable to retrieve the IDH status for about $14 \%$ of our cohort. The reason for this is that testing for a specific range of molecular parameters was not a standard diagnostic procedure only a few years prior. Partially missing information on IDH status is therefore rooted in this study's 10-year retrospective design. However, we were still able to provide more data on molecular parameters than have been provided in comparable papers. Information on MGMT promoter methylation was fairly complete with information missing for only $3 \%$ of all patients. Ultimately, MGMT promoter methylation status did not reach statistical significance in MVA and was therefore not considered for the construction of our score. Another genetic factor not analyzed here is CDKN2A (cyclin-dependent kinase inhibitor 2A). For IDH-mutant astrocytic gliomas, homozygous deletion of the CDKN2A gene has recently been shown to be a powerful predictor of poor outcome [19]. CDKN2A should therefore be evaluated as a potential factor for use in improved future versions of the score.

The second limitation of our study is related to the rapid changes in molecular testing and classification of astrocytoma in the past few years. The current 2016 WHO classification is already considered insufficient for grading and for forming prognostic groups, and an update is expected to be released by the end of 2020 [20]. It will likely progress away from the diagnosis of IDH-wildtype astrocytoma and consider these as cases of GBM. Consequently, all diffuse astrocytomas would be IDH-mutant and future prognostic scores with the potential of implementation in clinical routine will most probably include only IDH-mutant AA.

Thirdly, postoperative treatment in our cohort is very heterogenous. This illustrates the lack of suitable AA specific treatment guidelines until recently. Several historic studies have failed to demonstrate a universally superior postoperative treatment approach $[2,4,5,21]$. Until the CATNON trial, there was no basis for a general recommendation of combination therapy. The recent publication of the second interim analysis of the CATNON data will probably now lead to trimodal therapy being the new gold standard in treatment of IDH-mutant AA [7]. In our training cohort however, less than one fourth of the patients received trimodal therapy. We therefore consider a revised version of the score based on trimodally treated patients with IDH-mutant AA to be a reasonable next step in future research.

Fourthly, all data were acquired retrospectively and therefore were not recorded in accordance with a predefined study protocol. The KPS was not documented in some patients, and in general, the number of patients with a good KPS was relatively high in our cohort. Finally, it must be mentioned that at this point, our analysis and the score we constructed lack validation in an independent cohort.

\section{Conclusion}

We presented a model for a score that predicts the OS of patients newly diagnosed with AA. The scoring system requires four basic characteristics that are available at the time of histopathological confirmation of diagnosis: 
age, KPS, IDH status and extent of resection. None of the variables require additional diagnostic workup. The retrospective design of the results presented here should be considered. A validation of the score in an independent cohort is needed. In addition, future research must be in line with our growing understanding of molecular parameters, the changing treatment approaches, and the conclusions drawn in the upcoming revision of the WHO classification. A future version meeting these criteria could serve as a simple and useful tool in the choice of treatment regimen and patient consultations.

\begin{abstract}
Abbreviations
AA: Anaplastic astrocytoma; CTx: Chemotherapy; GBM: Glioblastoma; IDH: Isocitrate dehydrogenase; KPS: Karnofsky performance status; MGMT: $\mathrm{O}^{6}$-methylguanine-DNA-methyltransferase; MRI: Magnetic resonance imaging; MVA: Multivariable Cox regression analysis; OS: Overall survival; PFS: Progression-free survival; RCTx: Radiochemotherapy; RT: Radiotherapy; TMZ: Temozolomide; UVA: Univariate analysis; WHO: World Health Organization.
\end{abstract}

\section{Acknowledgements}

Not applicable.

\section{Authors' contributions}

HW collected data, performed statistical analysis and wrote part of the manuscript, DK planned the study, supervised the statistical analysis, wrote part of the paper and supervised the discussion of the manuscript; MT, KB, LS, JO, CS, $\mathrm{FE}$ and VB took part in the discussion of the manuscript. All authors read and approved the final manuscript.

\section{Funding}

Open Access funding enabled and organized by Projekt DEAL. This study did not receive external funding.

\section{Availability of data and materials}

Due to data protection regulations, the data analyzed for this paper cannot be shared on a publicly available repository.

\section{Ethics approval and consent to participate}

The study was approved by the ethics committee of Charité Universitätsmedizin Berlin. The study was conducted in accordance with the principles stated in the Declaration of Helsinki.

\section{Consent for publication}

Not applicable.

\section{Competing interests}

DK received travel grants from Accuray and is a member of the advisory board for Novocure. The authors declare that they have no competing interest related to the presented study.

\section{Author details}

${ }^{1}$ Department of Radiation Oncology, Charité University Hospital Berlin, Augustenburger Platz 1, 13353 Berlin, Germany. ${ }^{2}$ Department of Neuropathology, Charité University Hospital Berlin, Berlin, Germany. ${ }^{3}$ German Cancer Consortium (DKTK), Partner Site Berlin, German Cancer Research Center (DKFZ), Heidelberg, Germany. ${ }^{4}$ Department of Neurosurgery, Charité University Hospital Berlin, Berlin, Germany.

Received: 28 September 2020 Accepted: 6 December 2020

Published online: 17 December 2020

\section{References}

1. Louis DN, Perry A, Reifenberger G, von Deimling A, Figarella-Branger D, Cavenee WK, Ohgaki H, Wiestler OD, Kleihues P, Ellison DW. The 2016 World Health Organization classification of tumors of the central nervous system: a summary. Acta Neuropathol. 2016;131:803-20.

2. Wick W, Roth P, Hartmann C, Hau P, Nakamura M, Stockhammer F, Sabel MC, Wick A, Koeppen S, Ketter R, et al. Long-term analysis of the NOA-04 randomized phase III trial of sequential radiochemotherapy of anaplastic glioma with PCV or temozolomide. Neuro Oncol. 2016;18:1529-37.

3. Stupp R, Hegi ME, Mason WP, van den Bent MJ, Taphoorn MJB, Janzer RC, Ludwin SK, Allgeier A, Fisher B, Belanger K, et al. Effects of radiotherapy with concomitant and adjuvant temozolomide versus radiotherapy alone on survival in glioblastoma in a randomised phase III study: 5-year analysis of the EORTC-NCIC trial. Lancet Oncol. 2009;10:459-66.

4. Cairncross G, Wang M, Shaw E, Jenkins R, Brachman D, Buckner J, Fink K, Souhami L, Laperriere N, Curran W, Mehta M. Phase III trial of chemoradiotherapy for anaplastic oligodendroglioma: long-term results of RTOG 9402. J Clin Oncol. 2013;31:337-43.

5. Weller M, van den Bent M, Tonn JC, Stupp R, Preusser M, Cohen-JonathanMoyal E, Henriksson R, Rhun EL, Balana C, Chinot O, et al. European Association for Neuro-Oncology (EANO) guideline on the diagnosis and treatment of adult astrocytic and oligodendroglial gliomas. Lancet Oncol. 2017; 18:e315-29.

6. van den Bent MJ, Baumert B, Erridge SC, Vogelbaum MA, Nowak AK, Sanson M, Brandes AA, Clement PM, Baurain JF, Mason WP, et al. Interim results from the CATNON trial (EORTC study 26053-22054) of treatment with concurrent and adjuvant temozolomide for $1 \mathrm{p} / 19 \mathrm{q}$ non-co-deleted anaplastic glioma: a phase 3, randomised, open-label intergroup study. Lancet. 2017:390:1645-53.

7. Van Den Bent MJ, Erridge S, Vogelbaum MA, Nowak AK, Sanson M, Brandes AA, Wick W, Clement PM, Baurain J-F, Mason WP, et al. Second interim and first molecular analysis of the EORTC randomized phase III intergroup CATNON trial on concurrent and adjuvant temozolomide in anaplastic glioma without 1p/19q codeletion. J Clin Oncol. 2019:37:2000-2000.

8. Combs SE, Edler L, Rausch R, Welzel T, WickW, Debus J. Generation and validation of a prognostic score to predict outcome after re-irradiation of recurrent glioma. Acta Oncol. 2013;52:147-52.

9. Kessel KA, Hesse J, Straube C, Zimmer C, Schmidt-Graf F, Schlegel J, Meyer B, Combs SE. Validation of an established prognostic score after re-irradiation of recurrent glioma. Acta Oncol. 2017a;56:422-6.

10. Kessel KA, Hesse J, Straube C, Zimmer C, Schmidt-Graf F, Schlegel J, Meyer B, Combs SE. Modification and optimization of an established prognostic score after re-irradiation of recurrent glioma. PLOS ONE. 2017b;12:e0180457-e0180457.

11. Niyazi M, Adeberg S, Kaul D, Boulesteix AL, Bougatf N, Fleischmann DF, Grün A, Krämer A, Rödel C, Eckert F, et al. Independent validation of a new reirradiation risk score (RRRS) for glioma patients predicting postrecurrence survival: a multicenter DKTK/ROG analysis. Radiother Oncol. 2018;127:121-7.

12. Straube C, Kessel KA, Antoni S, Gempt J, Meyer B, Schlegel J, SchmidtGraf F, Combs SE. A balanced score to predict survival of elderly patients newly diagnosed with glioblastoma. Radiat Oncol. 2020;15:97.

13. Rades D, Conde-Moreno AJ, Cacicedo J, Veninga T, Segedin B, Stanic K, Schild SE. A scoring system to predict local progression-free survival in patients irradiated with $20 \mathrm{~Gy}$ in 5 fractions for malignant spinal cord compression. Radiat Oncol. 2018;13:257.

14. Malmström A, Grønberg BH, Marosi C, Stupp R, Frappaz D, Schultz H, Abacioglu U, Tavelin B, Lhermitte B, Hegi ME, et al. Temozolomide versus standard 6-week radiotherapy versus hypofractionated radiotherapy in patients older than 60 years with glioblastoma: the Nordic randomised, phase 3 trial. Lancet Oncol. 2012;13:916-26.

15. Scholtyssek F, Zwiener I, Schlamann A, Seidel C, Meixensberger J, Bauer M, Hoffmann KT, Combs SE, von Bueren AO, Kortmann RD, Müller K. Reirradiation in progressive high-grade gliomas: outcome, role of concurrent chemotherapy, prognostic factors and validation of a new prognostic score with an independent patient cohort. Radiat Oncol. 2013;8:161.

16. Combs SE, Niyazi M, Adeberg S, Bougatf N, Kaul D, Fleischmann DF, Gruen A, Fokas E, Rödel CM, Eckert F, et al. Re-irradiation of recurrent gliomas: pooled analysis and validation of an established prognostic score-report 
of the Radiation Oncology Group (ROG) of the German Cancer Consortium (DKTK). Cancer Med. 2018;7:1742-9.

17. Chapman CH, Hara JH, Molinaro AM, Clarke JL, Oberheim Bush NA, Taylor JW, Butowski NA, Chang SM, Fogh SE, Sneed PK, et al. Reirradiation of recurrent high-grade glioma and development of prognostic scores for progression and survival. Neurooncol Pract. 2019;6:364-74.

18. Niyazi M, Flieger M, Ganswindt U, Combs SE, Belka C. Validation of the prognostic Heidelberg re-irradiation score in an independent monoinstitutional patient cohort. Radiat Oncol. 2014:9:128

19. Shirahata M, Ono T, Stichel D, Schrimpf D, Reuss DE, Sahm F, Koelsche C, Wefers A, Reinhardt A, Huang K, et al. Novel, improved grading system(s) for IDH-mutant astrocytic gliomas. Acta Neuropathol. 2018;136:153-66.
20. von Deimling A, Ono T, Shirahata M, Louis DN. Grading of diffuse astrocytic gliomas: a review of studies before and after the advent of IDH testing. Semin Neurol. 2018;38:19-23.

21. Wick W, Platten M, Meisner C, Felsberg J, Tabatabai G, Simon M, Nikkhah G, Papsdorf K, Steinbach JP, Sabel M, et al. Temozolomide chemotherapy alone versus radiotherapy alone for malignant astrocytoma in the elderly: the NOA-08 randomised, phase 3 trial. Lancet Oncol. 2012;13:707-15.

\section{Publisher's Note}

Springer Nature remains neutral with regard to jurisdictional claims in published maps and institutional affiliations.
Ready to submit your research? Choose BMC and benefit from:

- fast, convenient online submission

- thorough peer review by experienced researchers in your field

- rapid publication on acceptance

- support for research data, including large and complex data types

- gold Open Access which fosters wider collaboration and increased citations

- maximum visibility for your research: over $100 \mathrm{M}$ website views per year

At BMC, research is always in progress.

Learn more biomedcentral.com/submissions 